\title{
Comparison of the Luminescent ADP-Glo Assay to a Standard Radiometric Assay for Measurement of Protein Kinase Activity
}

Jasbinder Sanghera, Rick Li, and Jun Yan

SignalChem Inc., Richmond, British Columbia, Canada.

\begin{abstract}
Many assay technologies have been developed and utilized to efficiently assay and screen against protein kinase targets. The radiometric assay format for assaying the protein kinase targets has been considered the "Gold Standard" format since it allows the direct readout of kinase functional activity and is a universal assay that is highly sensitive. However, the hazardous nature of the radiometric assay together with the regulatory hurdles has led to the development of alternative assay formats for assessing protein kinase activity measurements. The luminescent ADP-Glo ${ }^{T M}$ assay has been developed as an alternative to radiometric format for assaying protein kinase targets. This assay allows the measurement of the ADP product formed during the kinase reaction. Therefore, the luminescent ADP-Glo assay is similar to the radiometric format in that it measures the direct product of the protein kinase reaction. Furthermore, since the ADP product is generated by all protein kinase reactions, this is a universal format that can be used for assaying any given protein kinase target. Analysis of data generated with multiple protein kinase targets and the luminescent ADP-Glo technology shows comparable results to the radiometric assay format. Therefore, the luminescent ADP-Glo assay is a robust new technology for evaluating catalytic function of protein kinases as well as other ATPases.
\end{abstract}

\section{INTRODUCTION}

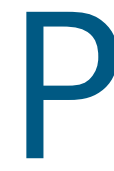

rotein kinases are the key mediators of messages in signaling pathways and defects in these proteins result in inappropriate signaling leading to disease development. ${ }^{1,2}$ Protein kinases catalyze the transfer of a phosphate group from ATP to a recipient protein, an event known as phosphorylation, while protein phosphatases catalyze a non-ATP-dependent reaction leading to the removal of the phosphatase group with transfer to water, an event known as dephosphorylation. The transmission of message within signaling pathways is therefore mediated by cascades of phosphorylation/dephosphorylation reactions that enable a cell to rapidly respond to various stimuli. The flow of message within signaling pathways culminate in changes in gene expression that result in up-regulation or down-regulation of gene expression leading to changes in cellular phenotype.

Due to the critical role of protein kinases in cell signaling, these proteins are normally under stringent control. Altered activities of these enzymes by either overexpression or mutations lead to changes in cellular response and the development of a disease state. Thus, these enzymes are considered excellent drug targets for therapeutic intervention. Therefore, there is a great interest in monitoring their activities, which requires the development of robust assay to meet these needs.

The radiometric assay format for protein kinases, which examines the direct incorporation of $\gamma-{ }^{33} \mathrm{P}$ from ${ }^{33} \mathrm{P}-\mathrm{ATP}$ into the protein kinase substrate, has long been considered the "gold standard" assay format. The rationale behind this assay format is the direct measurement of the rate of a given protein kinase reaction so that the catalytic activity can be accurately determined and quantitated. Furthermore, this assay format is a universal format for all protein kinase targets that gives high signal:background ratio with rapid readout. Therefore, using the radiometric assay format, new protein kinase targets can be easily studied once an appropriate substrate has been identified.

While the radiometric assay format displays nearly all the ideal attributes of a protein kinase assay, it does carry certain liabilities that have come under more intense scrutiny recently. These include the hazardous nature of the assay that requires special safety and environmental considerations as well as the

ABBREVIATIONS: SPA ${ }^{\mathrm{TM}}$, scintillation proximity assay; $\mathrm{HTRF}^{\mathrm{TM}}$, homogenous time resolved fluorescence; IMAPTM, immobilized metal affinity for phosphochemicals. 
technological challenges of assay miniaturization. Therefore, alternative protein kinase assay technologies have been developed and thoroughly investigated in order to identify the next generation of protein kinase assays that could replace the radiometric assay format. These protein kinase assays include $\mathrm{SPA}^{\mathrm{TM}}{ }^{3}$ HTRF $^{\mathrm{Tm}},{ }^{4}$ IMAP $^{\mathrm{Tm}},{ }^{5}$ and $Z^{\prime}$-LTYE ${ }^{\mathrm{Tm}} .{ }^{6}$ However, all these assays have some drawbacks that include the use of radioisotope, dependency on antibody, requirement for special peptide substrate, and the long assay time. Recently, the luminescent Kinase-Glo assay ${ }^{7}$ became available for protein kinase assays and this assay technology addressed a number of the limitations of the previous assays. The Kinase-Glo assay measured ATP consumption and is a homogeneous, universal assay that does not require radioisotope and antibody utilization. However, while the Kinase-Glo assay works extremely well for highly active protein kinase preparations, the signal:background ratio for the less active protein kinase targets is sub-optimal. The main reason for this effect is that not enough ATP is utilized by the protein kinase in the reaction in order to generate a significant signal above background. Therefore, more improvements have been sought for this assay format and this eventually has led to the development of the luminescent ADP-Glo ${ }^{\mathrm{TM}}$ assay, which measures the generation of ADP during the protein kinase reaction. In the present study, the luminescent ADP-Glo assay has been extensively investigated in order to assess whether it can be considered as a true alternative to radiometric format for assaying protein kinase targets. The attributes of the luminescent ADP-Glo assay have been characterized and compared against the radiometric assay format during evaluation of protein kinase activity and the compound profiling process.

\section{MATERIALS}

The various protein kinase and heat shock protein (HSP) targets employed in the enzyme activity measurements and compound profiling process were cloned, expressed, and purified in-house at SignalChem using proprietary methods. Quality control testing is routinely performed on each of the SignalChem targets to ensure compliance to acceptable laboratory standards. Protein kinase substrates employed in the enzyme activity measurements and compound profiling process were synthesized internally. The luminescent ADP-Glo assay kit and the GloMax luminometer were from Promega (Madison, WI). The various protein kinase inhibitors were purchased from EMD Biosciences (San Diego, CA). ${ }^{33}$ P-ATP was purchased from PerkinElmer (Shelton, CT). The 96-well round bottom reaction plates were from Corning (Lowell, MA). All other materials were of standard laboratory grade.

\section{METHODS}

\section{Measurement of Protein Kinase Activity \pm Inhibitor} Using Radiometric Assay Format

The radiometric assay format measures the direct incorporation of $\gamma-{ }^{33} \mathrm{P}$ from ${ }^{33} \mathrm{P}-\mathrm{ATP}$ into the protein kinase substrate. The assay condition for the various protein kinase targets was optimized to yield acceptable enzymatic activity and a high signal:background ratio. All radiometric assays were performed in a designated radioactive working area. Protein kinase assays (in duplicate) were performed at $30^{\circ} \mathrm{C}$ for $15 \mathrm{~min}$ in a final volume of $25 \mu \mathrm{L}$ according to the following assay reaction recipe: $5 \mu \mathrm{L}$ of diluted active protein kinase target $(\sim 10-50 \mathrm{nM}$ final protein concentration in the assay), $5 \mu \mathrm{L}$ of stock solution of appropriate substrate (1-5 $\mathrm{\mu g}$ of peptide or protein substrate), $5 \mu \mathrm{L}$ of kinase assay buffer or protein kinase activator in kinase assay buffer, 5 $\mu \mathrm{L}$ of protein kinase inhibitor or assay buffer, $5 \mu \mathrm{L}$ of ${ }^{33} \mathrm{P}$-ATP $(250$ $\mu \mathrm{M}$ stock solution, $0.8 \mu \mathrm{Ci}$ ).

The assay was initiated by the addition of ${ }^{33} \mathrm{P}-\mathrm{ATP}$ and the reaction mixture was incubated at $30^{\circ} \mathrm{C}$ for $15 \mathrm{~min}$. After the incubation period, the assay was terminated by spotting $10 \mu \mathrm{L}$ of the reaction mixture onto Multiscreen phosphocellulose P81 plate. The Multiscreen phosphocellulose P81 plate was washed

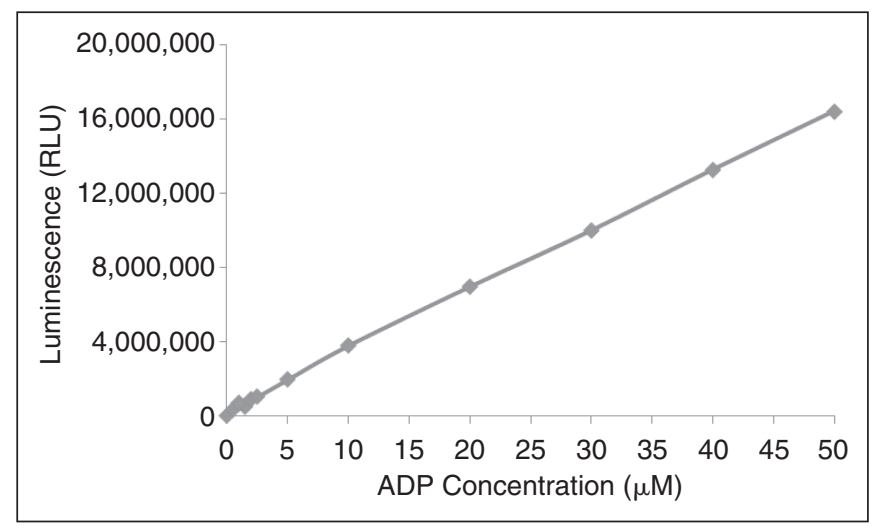

Fig. 1. Correlation of \% ATP conversion to ADP using the ADP-Glo ${ }^{T M}$ assay. The ratio of ATP and ADP was varied in a 96-well plate using a total reaction volume of $25 \mu \mathrm{L}$. Starting with $50 \mu \mathrm{M}$ ATP (100\%), the level was sequentially decreased down to $0 \%$, while the ADP level was correspondingly increased to $100 \%(50 \mu \mathrm{M})$. The reaction volume remained constant at $25 \mu \mathrm{L}$. The luminescence signal (presented in RLUs, or relative light units) at different ATP/ADP levels was determined by adding $25 \mu \mathrm{L}$ of ADP-Glo reagent. The 96-well plate was shaken and then incubated for $40 \mathrm{~min}$ at ambient temperature. Then $50 \mu \mathrm{L}$ of Kinase Detection Reagent was added, the 96-well plate was shaken and then incubated for further $30 \mathrm{~min}$ at ambient temperature. The 96 -well reaction plate was then read using the ADP-Glo Luminescence Protocol on a GloMax plate reader. 
3 times for $\sim 15$ min each in a 1\% phosphoric acid solution. The radioactivity on the $\mathrm{P} 81$ plate was counted in the presence of scintillation fluid in a Trilux scintillation counter.

Blank controls were set up for each protein kinase target, which included all the assay components except the addition of the appropriate substrate (replaced with equal volume of assay dilution buffer). The corrected activity for each protein kinase target was determined by subtracting the blank control from experimental values.

\section{Measurement of Protein Kinase Activity Using ADP-Glo}

Protein kinase assays were performed using the luminescent ADP-Glo assay kit from Promega that measures the generation of ADP by the protein kinase reaction. Generation of ADP by the protein kinase reaction leads to an increase in luminescence signal in the presence of luminescent ADP-Glo assay kit.

The protein kinase assays were performed at $30^{\circ} \mathrm{C}$ for $15 \mathrm{~min}$ in a final volume of $25 \mu \mathrm{L}$ according to the following assay reaction recipe: $5 \mu \mathrm{L}$ of diluted active protein kinase target $(\sim 10-50 \mathrm{nM}$ final protein concentration in the assay), $5 \mu \mathrm{L}$ of stock solution of appropriate substrate (1-5 $\mu \mathrm{g}$ of peptide or protein substrate, this represents $2-3 \times K_{\mathrm{m}}$ value), $5 \mu \mathrm{L}$ of kinase assay buffer or protein kinase activator in kinase assay buffer, $5 \mu \mathrm{L}$ of protein kinase inhibitor or assay buffer, $5 \mu \mathrm{L}$ of ATP $(250 \mu \mathrm{M}$ stock solution, this represent $5-10 \times K_{\mathrm{m}}$ value).

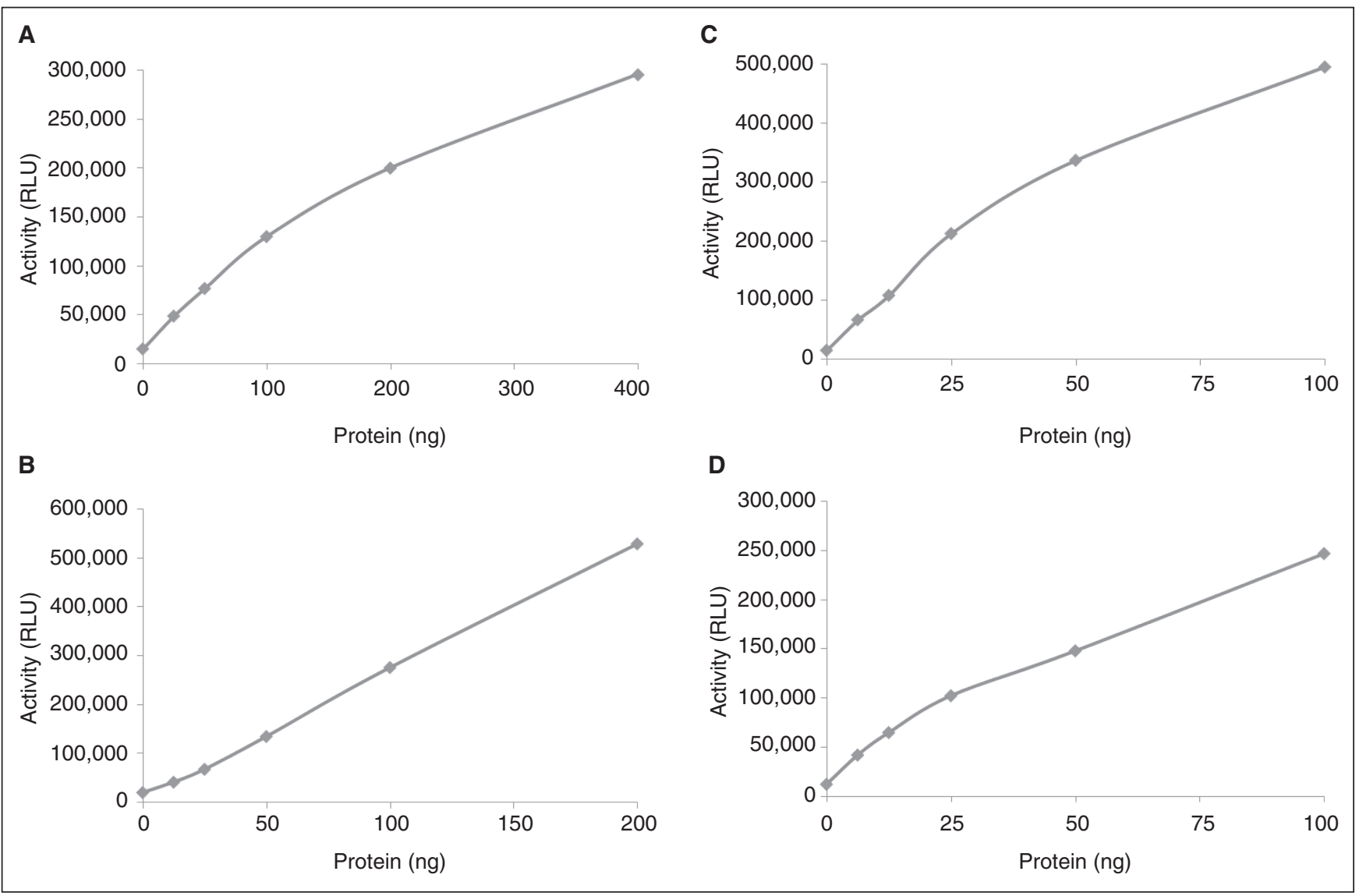

Fig. 2. Protein kinase dilution curves using the ADP-Glo ${ }^{T M}$ assay. Six-point enzyme dilution curves were generated using a tyrosine kinase TRKA (A), a serine/threonine kinase AKT1 (B), a dual specificity kinase MEK1 (C), and a lipid kinase p110 $\alpha / p 85 \alpha \mathrm{PI} 3 \mathrm{~K}$ (D). The various protein kinase targets were assayed at increasing protein concentrations using the appropriate substrate at $30^{\circ} \mathrm{C}$ for 15 min in a final volume of $25 \mu \mathrm{L}$ using a 96-well plate. After the 15 -min incubation period, the assay was terminated by the addition of $25 \mu \mathrm{L}$ of ADP-Glo reagent. The 96-well plate was shaken and then incubated for $40 \mathrm{~min}$ at ambient temperature. Then $50 \mu \mathrm{L}$ of Kinase Detection Reagent was added, the 96-well plate shaken and then incubated for further $30 \mathrm{~min}$ at ambient temperature. The 96 -well reaction plate was then read using the ADP-Glo Luminescence Protocol on a GloMax plate reader. Abbreviation: RLU, relative light unit. 
The assay was started by incubating the reaction mixture in a 96 -well plate at $30^{\circ} \mathrm{C}$ for $15 \mathrm{~min}$. After the 15 -min incubation period, the assay was terminated by the addition of $25 \mu \mathrm{L}$ of ADP-Glo reagent. The 96-well plate was shaken and then incubated for $40 \mathrm{~min}$ at ambient temperature $\left(20^{\circ} \mathrm{C}-22^{\circ} \mathrm{C}\right)$. Then 50 $\mu \mathrm{L}$ of Kinase Detection Reagent was added, the 96 -well plate was shaken and then incubated for further $30 \mathrm{~min}$ at ambient temperature. The 96-well reaction plate was then read using the ADP-Glo Luminescence Protocol on a GloMax plate reader.

Blank controls were set up that included all the assay components except the addition of the protein kinase substrate (replaced with equal volume of kinase assay buffer). The corrected activity for protein kinase target was determined by subtracting the blank control from experimental values.

\section{RESULTS}

\section{ADP-ATP Standard Curve}

The luminescent ADP-Glo assay is a non-radioisotope, homogeneous, high-throughput protein kinase assay that quantitates the amount of ADP generated during the protein kinase reaction. The ADP generated by the protein kinase reaction is quantitated in a 3-step fashion. First, the residual ATP is completely depleted after completion of the protein kinase reaction so that only the ADP generated remains. This is followed by conversion of all the ADP to ATP. Finally, the newly formed ATP is then utilized in the process of monooxygenation of luciferin by luciferase, which results in the luminescence signal being generated that is subsequently detected with a luminometer.

To investigate the linearity and sensitivity of the ADP-Glo assay, the ratio of ADP to ATP was adjusted from 100\% ATP to
100\% ADP, using a 10-point dilution curve. The objective of these studies is to find out whether signal generated is proportional to the amount of ADP present. Various amounts of ADP/ATP ratio were utilized (final concentration of $50 \mu \mathrm{M}$ for each) in a total volume of $25 \mu \mathrm{L}$ using a 96-well round bottom. Then an equal volume $(25 \mu \mathrm{L})$ of ADP-Glo reagent was added and the mixture incubated for $40 \mathrm{~min}$ at ambient temperature. Subsequently, $50 \mu \mathrm{L}$ of Kinase Detection Reagent was added and the reaction incubated for $30 \mathrm{~min}$ at ambient temperature. The 96-well reaction plate was then read using the ADP-Glo Luminescence Protocol on a GloMax plate reader. As shown in Figure 1, increasing amounts of ADP in the reaction mixture led to a linear increase in the luminescence signal. Furthermore, the signal:background ratio was still at an acceptable level $(>4)$ even at very low ADP concentration $(<10 \%)$. Therefore, even in the presence of very low level of ADP, the ADPGlo assay is sensitive enough to measure a protein kinase reaction. Thus, determining the enzyme activity of less active protein kinase targets should be easily performed using ADP-Glo.

\section{Activity Determination of Protein Kinase Targets Using} the Radiometric and ADP-Glo Assays

To initially investigate the utility of the ADP-Glo assay for measuring protein kinase activity, protein kinase dilution curves were generated using a diverse panel of targets. The targets included TRKA (tyrosine kinase, Genbank \# NM_002529), AKT1 (serine/ threonine kinase, Genbank \# NM_005163), MEK1 (dual specificity kinase, Genbank \# NM_002755), and PI3K (lipid kinase, Genbank \# NM_008839) and 6-point enzyme dilution curves were generated with these targets. As shown in Figure 2, all the protein kinase targets generated good activity curves with ADP-Glo. As

\begin{tabular}{l} 
Table 1. Signal:Background Ratio Determination of Various Protein Kinase Targets Using the Radiometric and ADP-Glo ${ }^{\text {TM }}$ Assays \\
\cline { 2 - 6 } \\
\cline { 2 - 6 }
\end{tabular}

Various protein kinase targets were assayed using the radiometric and ADP-Glo assays. Same amount of protein for each protein kinase target was used for assay using the radiometric and ADP-Glo assays. The blank value (contains no substrate) and the control value (contains appropriate substrate) were determined for each protein kinase target. The signal:background (S/B) ratio for each protein kinase target was calculated by dividing the control value by the blank value.

Abbreviations: CPM, counts per minute; RLU, relative light unit. 
the concentration of the protein kinase targets increased, higher luminescence signal was obtained. Initially, the protein kinase activity curves are approximately linear and then at higher protein kinase concentration, they start to plateau that may be due to substrate depletion and/or enzyme inactivation. Thus, the ADPGlo demonstrates broad utility in that it can be used to measure protein kinase activity of diverse targets including tyrosine, serine/threonine, dual specificity, and lipid kinases.

\section{Activity Determination of Protein Kinase Targets Using} the Radiometric and ADP-Glo Assays

To further establish how robust and similar in characteristics the ADP-Glo assay is in comparison to the radiometric assay, a diverse set of the protein kinase targets were utilized and the signal:background ratio examined at a single protein kinase concentration. The protein kinase concentration was chosen from previous in-house characterization of the appropriate protein kinase target that had given a good signal with the radiometric assay. Table 1 shows that all the selected diverse protein kinase targets involved in a variety of signaling pathways give a good signal:background ratio with the radiometric assay. The signal:background ratio is in the range of 10-100. Furthermore, the ADP-Glo assay also showed a good signal:background ratio for all the protein kinase targets and the values are within the range of the values obtained with the radiometric assay. Therefore, the ADP-Glo assay gives good signal:background values for a diverse set of protein kinase targets and the values are in close agreement with those generated by the radiometric assay. These data provide strong evidence that the activity signal for diverse set of protein kinases is comparable to that of the radiometric assay.

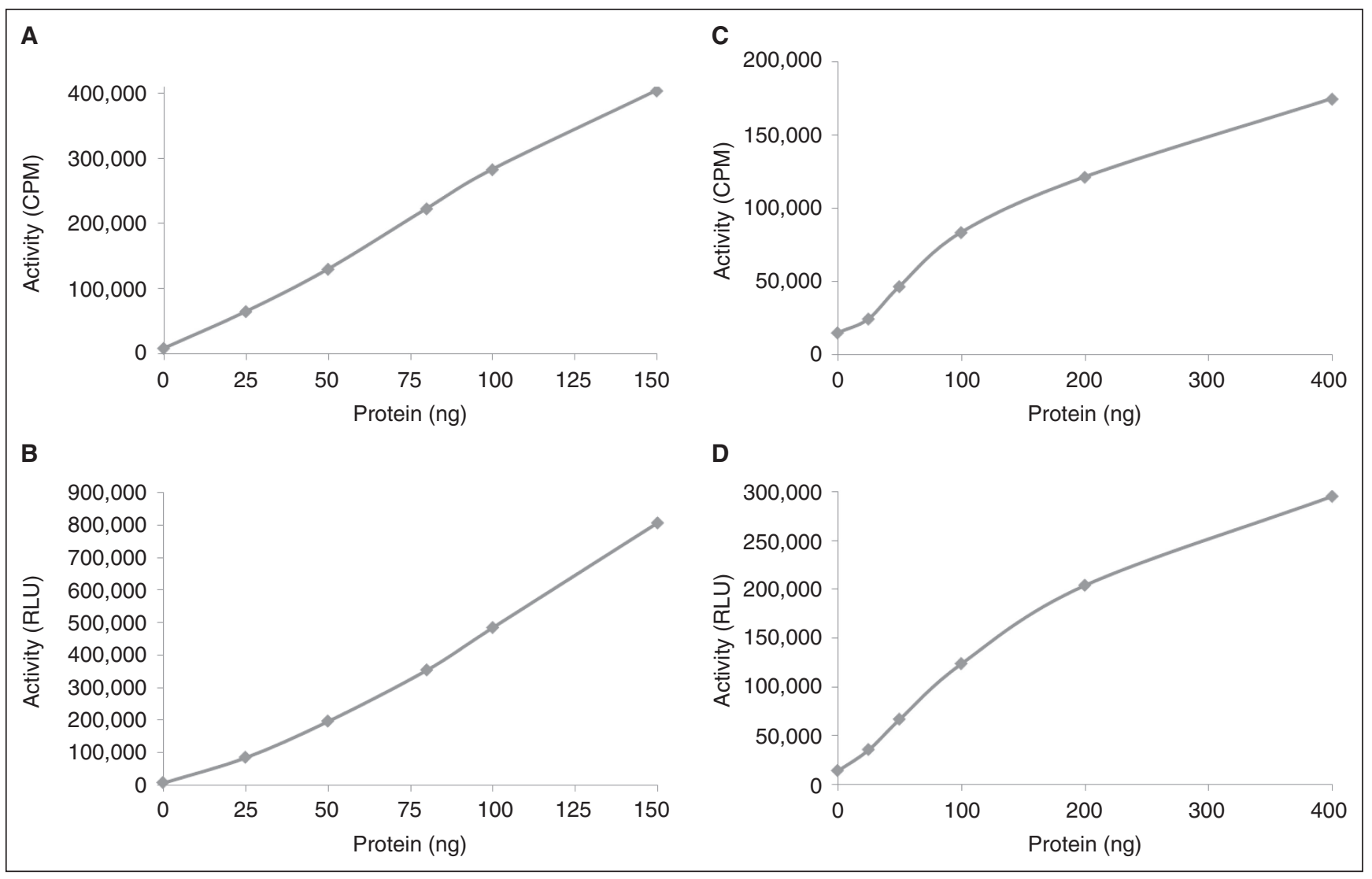

Fig. 3. Comparison of protein kinase dilution curves using the radiometric and ADP-Glo ${ }^{T M}$ assays. Six-point enzyme dilution curve was generated with a serine/threonine kinase GSK3 3 using the radiometric assay (A) or the ADP-Glo assay (B). A 6-point enzyme dilution curve was also generated with a tyrosine kinase TRKA using the radiometric assay (C) or the ADP-Glo assay (D). The GSK3 $\beta$ and TRKA protein kinase target was assayed at increasing protein concentrations using the appropriate substrate at $30^{\circ} \mathrm{C}$ for 15 min in a final volume of $25 \mu \mathrm{L}$ using a 96-well plate. For the radiometric assay, ${ }^{33}$ P-ATP was utilized to follow the reaction, while for the ADP-Glo assay, ADP-Glo reagent and Kinase Detection Reagent were utilized. Abbreviations: CPM, counts per minute; RLU, relative light unit. 
To further compare the radiometric and ADP-Glo assays, 6-point protein kinase dilution curves were performed using a tyrosine kinase TRKA and a serine/threonine kinase GSK3 $\beta$ with the radiometric and ADP-Glo assays. As shown in Figure 3, both assay format yielded protein kinase activity curves that were almost identical. The GSK3 $\beta$ targets showed an approximate linear increase in activity with increasing enzyme concentration with both the radiometric and ADP-Glo assays (Fig. $3 A$ and $3 B$ ). The specific activity of the GSK3 $\beta$ was determined from the radiometric and ADP-Glo graphs. The radiometric assay yielded a specific activity value of $111 \mathrm{nmol} / \mathrm{min} / \mathrm{mg}$, while the ADPGlo assay yielded a specific activity value of $102 \mathrm{nmol} / \mathrm{min} / \mathrm{mg}$. Therefore, both the radiometric and the ADP-Glo assay methods generate specific activity values that are very similar.

A 6-point dilution curve with TRKA also showed an initial linear increase in activity that starts to plateau at higher protein kinase concentration with both assay formats (Fig. 3C and 3D). The specific activity of the TRKA was determined from the radiometric and ADP-Glo graphs. The radiometric assay yielded a specific activity value of $23 \mathrm{nmol} / \mathrm{min} / \mathrm{mg}$, while the ADP-Glo assay yielded a specific activity value of $19 \mathrm{nmol} / \mathrm{min} / \mathrm{mg}$. Therefore, this is further evidence that the ADP-Glo assay displays characteristics similar to the radiometric assay format.

Activity Determination of Protein Kinase Targets in the Presence of Inhibitor Compounds Using the Radiometric and ADP-Glo Assays

To further establish how reliable the ADP-Glo assay is in comparison to the radiometric assay, protein kinase assays were performed in the presence various inhibitor compounds and then the $\mathrm{IC}_{50}$ values determined. The goal of these studies is to establish whether the radiometric assay and ADP-Glo assay yield similar $\mathrm{IC}_{50}$

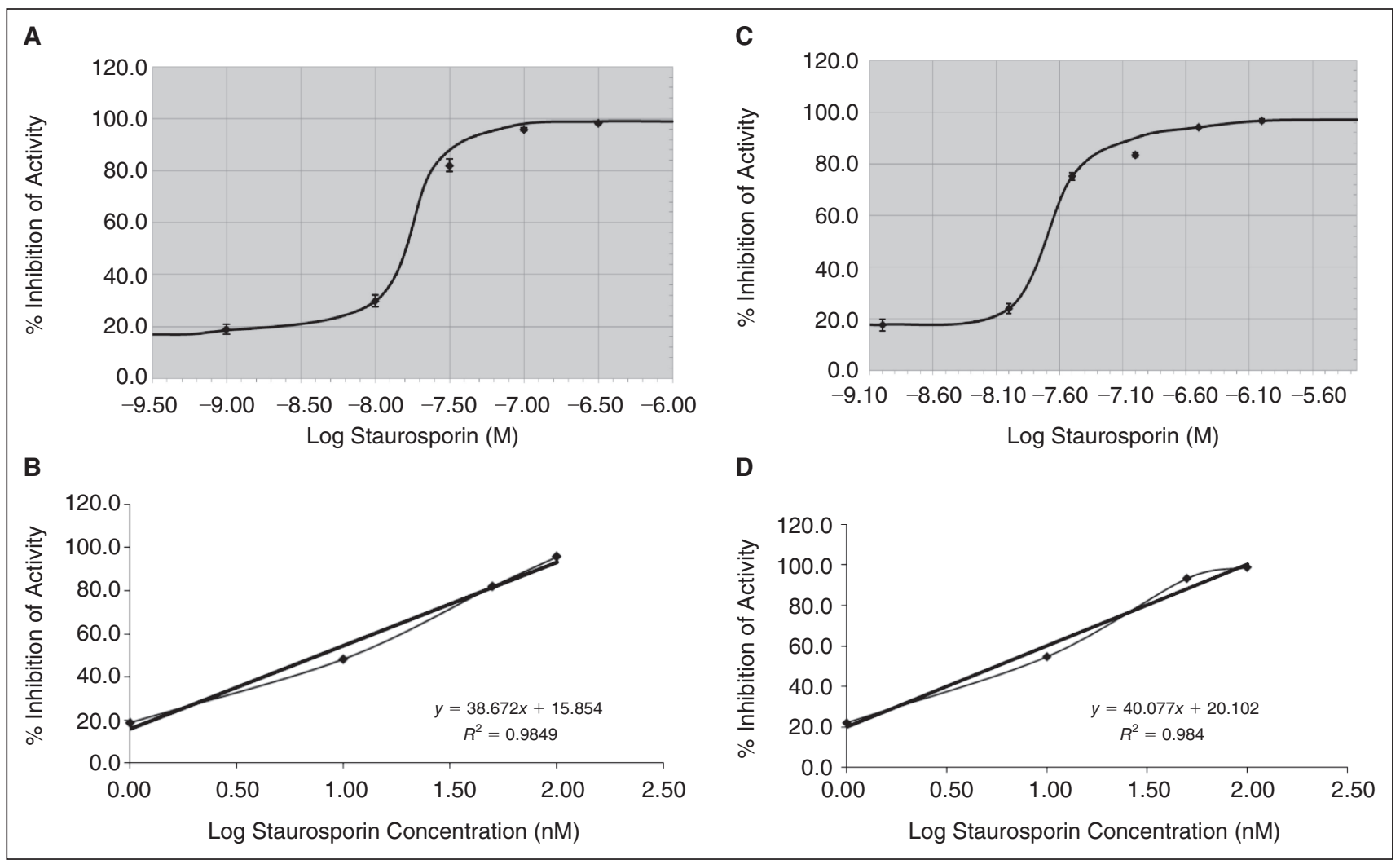

Fig. 4. Comparison of $\mathrm{IC}_{50}$ curve for staurosporin against RSK1 using the radiometric and ADP-Glo ${ }^{\mathrm{TM}}$ assays. Six-point concentration curve for staurosporin was generated with a serine/threonine kinase RSK1 using the radiometric assay (A and B) or the ADP-Glo assay (C and D). The RSK1 protein kinase target was assayed using the appropriate substrate in the presence of increasing staurosporin concentrations at $30^{\circ} \mathrm{C}$ for $15 \mathrm{~min}$ in a final volume of $25 \mu \mathrm{L}$ using a 96-well plate. For the radiometric assay, ${ }^{33}$ P-ATP was utilized to follow the reaction, while for the ADP-Glo assay, ADP-Glo reagent and Kinase Detection Reagent were utilized. 


\section{LUMINESCENT ADP-Glo ASSAY FOR KINASE ACTIVITY}

\begin{tabular}{|c|c|c|c|}
\hline Target & Compound & Radiometric Assay IC so $_{5}$ Value & ADP-Glo Assay $I_{50}$ Value \\
\hline RSK1 & Staurosporin & $7.6 \mathrm{nM} \pm 0.5$ & $5.6 \mathrm{nM} \pm 0.3$ \\
\hline PKA & H89 & $79 \mathrm{nM} \pm 4.3$ & $85 \mathrm{nM} \pm 3.2$ \\
\hline RSK1 & BI-D1870 & $25 \mathrm{nM} \pm 1.4$ & $22 \mathrm{nM} \pm 1.6$ \\
\hline TRKA & Tyrophostin AG 879 & $22 \mathrm{nM} \pm 1.1$ & $29 \mathrm{nM} \pm 2.1$ \\
\hline $\mathrm{PKC} \alpha$ & H7 & $88 \mathrm{nM} \pm 3.3$ & $97 \mathrm{nM} \pm 4.2$ \\
\hline p38 $\alpha$ & SB202190 & $120 \mathrm{nM} \pm 4.2$ & $150 \mathrm{nM} \pm 2.3$ \\
\hline CDK2/cyclin A2 & Roscovitine & $325 \mathrm{nM} \pm 6.7$ & $389 n M \pm 8.3$ \\
\hline
\end{tabular}

Various protein kinase targets were assayed in the presence of increasing compound concentrations (8-point concentration curve) using the radiometric and ADP-Glo assays. The $\mathrm{IC}_{50}$ value for each compound against a given target was determined by plotting a graph of log compound concentration against \% inhibition of protein kinase activity. A best-fit line graph was generated and the slope of the line used to calculate the $I C_{50}$ value. The error value represents standard error of $n=2$ values.

values. Initially, the effect of staurosporin on the protein kinase RSK1 was examined. As shown in Figure $4 A$ and $4 B$, the radiometric assay showed a significant decrease in RSK1 activity with increasing staurosporin concentration and an $\mathrm{IC}_{50}$ value of $\sim 7.6 \mathrm{nM}$ was obtained (derived from the best-fit lined graph where the $R$ value was 0.984). The ADP-Glo assay also showed a significant decrease in RSK1 activity with increasing concentrations of staurosporin (Fig. $4 \mathrm{C}$ and $4 D$ ) and an $\mathrm{IC}_{50}$ value of $\sim 5.6 \mathrm{nM}$ (derived from the best-fit lined graph where the $R$ value was 0.984). Therefore, these results indicate that both the radiometric and ADP-Glo assays generated $\mathrm{IC}_{50}$ values are approximately similar and this indicates that the 2 assay methods are capable of detecting potent inhibitors of protein kinase activity with similar $\mathrm{IC}_{50}$.

To further compare the similarities between the radiometric and ADP-Glo assays using multiple protein kinase targets in the presence of various inhibitor compounds, 8-point $\mathrm{IC}_{50}$ curves were generated. As shown in Table 2, the $\mathrm{IC}_{50}$ values generated with tool compound for each kinase target showed comparable results between the radiometric and ADP-Glo assays. There is no significant difference between the values generated by both assay methods and the values are in the range of $\mathrm{IC}_{50}$ values reported in the literature. ${ }^{8}{ }^{9}$ Therefore, this is additional evidence that the ADP-Glo assay displays characteristics similar to the radiometric assay format.

\section{DISCUSSION}

The present study was undertaken in order to assess whether the ADP-Glo can be used to assay protein kinase targets. The aim was to determine whether different protein kinases (eg, tyrosine, serine/threonine, lipid, and dual specificity protein kinases) can be assayed with ADP-Glo successfully and if so, how do the results compare when these targets are also assayed using the "gold standard" radiometric assay.

The results showed that ADP-Glo can be utilized to assay different types of protein kinase targets with varying levels of protein kinase activity. This is an important finding since other assay methods have not shown reasonably good data with protein kinase targets that are not highly active. Furthermore, since the different types of targets showed good activity, this also demonstrates the broad utility of the ADP-Glo assay method.

The results obtained with the radiometric assay are replicated with the ADP-Glo assay method. Similar activity curves are generated by both assay methods with different protein kinase targets and the signal:background ratios are comparable. Furthermore, similar specific activity values are obtained for various protein kinase targets. This further supports the notion that the ADP-Glo assay is a viable alternative to the radiometric assay for determining protein kinase activity. Lastly, the data examining the effect of various compounds on diverse set of protein kinase targets validates ADP-Glo assay as robust and efficient method that is comparable to the radiometric assay.

In conclusion, the data generated in the present study supports the notion that the ADP-Glo is an ideal assay format for determining protein kinase activity as well as performing compound profiling with protein kinase inhibitors. The ADP-Glo assay offers all the desirable attributes but obviates the liabilities of the radiometric assay. Therefore, the luminescent ADP-Glo assay can now be seriously considered as the next "gold standard" assay format for protein kinase activity.

\section{AUTHOR DISCLOSURE STATEMENT}

J.S., R.L., and J.Y. are employees of SignalChem Inc. 


\section{SANGHERA, LI, AND YAN}

\section{REFERENCES}

1. Hunter T: Signaling-2000 and beyond. Cell 2000;100:113-127.

2. Cohen P: Protein kinases-the major drug targets of the twenty-first century? Nat Rev Drug Discov 2002;1:309-315.

3. Klob AJ, Kaplita PV, Hayes DJ, Park YW, Pernell C, Major JS, et al.: Tyrosine kinase assay adapted to homogeneous time-resolved fluorescence. Anal Biochem 1997;253:210-218.

4. Rodems SM, Hamman BD, Lin C, Zhao J, Shah S, Heidary D, et al:: A FRET-based assay platform for ultra-high density drug screening of protein kinases and phosphatases. Assay Drug Dev Technol 2002;1:9-19.

5. Loomans EEMG, van Doornmalen AM, Wat JWY, Zaman GJR: High-throughput screening with immobilized metal ion affinity-based fluorescence polarization detection, a homogenous assay for protein kinases. Assay Drug Dev Technol 2003;1:445-453.

6. Zaman GJR, Garritsen A, Boer T, Boeckel CAA: Fluorescence assay for highthroughput screening of protein kinases. Comb Chem High Throughput Screen 2003;6:313-320.
7. Koresawa M, Okabe T: High-throughput screening with quantitation of ATP consumption: A universal non-radioisotope homogenous assay for protein kinases. Assay Drug Dev Technol 2004;2:153-160.

8. Davies SP, Reddy H, Caivano M, Cohen P: Specificity and mechanism of action of some commonly used protein kinase inhibitors. Biochem J 2000;351:95-105.

9. Bain J, Mclauchlan $H_{1}$ Elliott $M$, Cohen $P$ : The specificities of protein kinase inhibitors: an update. Biochem J 2003;371:199-204.

Address correspondence to: Dr. Jasbinder Sanghera SignalChem Inc. 550-5600 Parkwood Way Richmond, BC V6V $2 M 2$

Canada

E-mail: jsanghera@signalchem.com 